\title{
DOS POSSÍVEIS AO NECESSÁRIO OS PERCURSOS DE ANSELMO DE AOSTA E DE TOMÁS DE AQUINO
}

\author{
Maria Inês Bolinhas \\ Universidade Católica Portuguesa - Lisboa
}

Procuramos neste estudo determinar as convergências e as divergências existentes entre a terceira via de Anselmo de Aosta e a terceira via de Tomás de Aquino. O intuito não é o de mostrar uma relação de filiação, directa ou indirecta, da terceira via tomista na terceira via anselmiana, uma vez que é certo que Anselmo não figura entre as fontes da terceira via tomista ${ }^{1}$; trata-se, sim, de determinar se a solução apresentada no Monologion antecede de algum modo a encontrada quer na Suma de Teologia quer na Suma contra os Gentios.

Embora prossigam por caminhos diferentes, as terceiras vias de Anselmo e de Tomás têm em comum quer o ponto de partida quer o ponto de chegada: ambas arrancam da existência dos entes contingentes e concluem pela necessidade da existência do ente necessário per se. Haverá alguma semelhança nos passos que as conduzem à conclusão? Para melhor responder a esta pergunta, reflectimos a três tempos: em primeiro lugar, procedemos a uma breve descrição da terceira via anselmiana; em segundo, da terceira via tomista (na Suma contra os Gentios e na Suma de Teologia); em terceiro, a uma análise comparada das duas, primeiramente quanto à estrutura argumentativa e, seguidamente, quanto aos princípios metafísicos que as suportam.

${ }^{1}$ Com efeito, a via ex possibili et necessario foi moldada a partir de Avicena e, muito particularmente, de Moisés Maimónides. Para um aprofundamento desta questão, cf. os seguintes estudos: Étienne Gilson, Le Thomisme. Introduction à la philosophie de saint Thomas d'Aquin, Paris, Vrin, 71997, pp. 79-81; Avital Wohlman, Thomas d'Aquin et Maïmonide. Un dialogue exemplaire, Paris, Cerf, 1988, pp. 60$-67$.

Philosophica, 34, Lisboa, 2009, pp. 277-292 


\section{A terceira via anselmiana}

Após mostrar, na primeira via, que a suma bondade é a razão da bondade das coisas boas e, na segunda, que a suma grandeza é a razão da grandeza das coisas grandes, o Doutor Magnífico empenha-se em tornar claro que o sumo ser é a razão de ser de todas as coisas que são. Assim, a terceira via não versa especificamente sobre o ser que é dito bom ou grande, mas sobre o próprio ser, que, precisamente por ser, pode ser dito bom ou grande. Este argumento assume, pois, os precedentes, sedimentando o caminho para o quarto, sobre a gradação da perfeição da natureza das coisas que são.

A prova parte da existência indesmentível dos entes. Anselmo começa por retomar as conclusões das vias anteriores e adianta uma suposição que assume a força de hipótese: se as coisas boas são boas em virtude de alguma coisa sumamente boa e as coisas grandes são grandes em virtude de alguma coisa sumamente grande, o mesmo se passará com o ser (esse), pois tudo o que é/existe, é/existe por uma qualquer coisa (quidquid est, per unum aliquid videtur esse ${ }^{2}$ ).

Seguidamente, o leitor é confrontado com uma disjunção: tudo aquilo que é/existe, é/existe ou por alguma coisa ou por nada (omne quod est, aut est per aliquid aut per nihil). Assim posta, a alternativa permite-nos compreender que na terceira via o ente é tomado como ser em relação. $O$ ente é ser por algo (esse per aliquid); ser ente é ser em virtude de algo que é outro, é ser efeito de um outro, ao qual se refere como à sua causa ${ }^{3}$. Anselmo não trata aqui, pois, da existência necessária, mas apenas da possível.

A disjunção apresentada é prontamente resolvida. Não é pensável que algo exista (ou possa vir a existir) a partir do nada, porque nada é em virtude do nada, pelo que há que concluir que tudo o que existe existe necessariamente por qualquer coisa. Solucionada a alternativa, abre-se uma nova questão. Sabe-se que o que existe, existe em virtude de alguma coisa. Mas de que tipo? Uma única coisa ou várias coisas?

A respeito da possibilidade de a causa da existência de tudo quanto é ser, não una, mas múltipla, o Doutor Magnífico enuncia três hipóteses. Essas muitas coisas ou se referem a uma mesma coisa pela qual são, ou cada uma delas é por si, ou são reciprocamente (causas e causadas) umas pelas outras (aut ipsa referentur ad unum aliquid per quod sunt, aut ea-

2 Cf. Monologion 3. Todas as citações do Monologion foram feitas a partir da edição crítica de F. S. Schmitt, reproduzida em L'Oeuvre d'Anselme de Cantorbéry, intr., trad. e notas de Michel Corbin, s.j., t. I, Les Éditions du Cerf, Paris, 1986.

3 Cf. Maria Leonor Xavier, «O argumento anselmiano entre continuadores e críticos», in Idem (org.), A Questão de Deus na História da Filosofia, vol. I, Sintra, Zéfiro, 2008, pp. 269-326; p. 271. 
dem plura sint per se, aut per se invicem sunt). O enunciado da primeira hipótese revela-se contraditório. Com efeito, se os múltiplos são/existem em virtude de um (ente), então são (e com eles tudo é), na verdade, per unum, e não per plura ${ }^{4}$. A segunda hipótese é também eliminada à partida. Se os múltiplos fossem/existissem cada um por si mesmo, então teriam em comum o próprio facto de serem por si (per se). Haveria forçosamente que supor uma qualquer força ou natureza existente (aliqua vis vel natura existendi), per se, em virtude da qual eles seriam, também, per se. Assim, os muitos seriam, na verdade, em virtude de um único, e não de muitos. Resta analisar a terceira hipótese: se os múltiplos poderão ser/existir causando-se reciprocamente, sendo cada um a razão da existência do outro. A resposta a esta última hipótese é categórica: não é possível - este pensamento é irracional (irrationabilis cogitatio), porque nada pode ser por aquilo a que deu o ser.

A incoerência lógica inerente a cada uma destas três hipóteses que postulam o múltiplo como a causa da existência do múltiplo obriga a descartá-las em bloco e a afirmar a necessidade de que aquilo pelo qual todas as coisas existentes existem seja um só (necesse est unum illud esse, per quod sunt cuncta quae sunt). Tudo o que é, é em virtude deste um; e apenas ele é por si mesmo.

Após estabelecer que as múltiplas coisas que existem, existem por um único, Anselmo esclarece que este sumo ser/existente per se não pode senão ser o sumo bem e a suma grandeza. Na verdade, o que existe por outro é menos do que aquilo pelo qual existem todas as coisas - e que é o único que existe per se; ou, na formulação inversa, aquilo que existe per se é da maior (logo, melhor) maneira de todas (maxime omnium est). Este esse per se identifica-se assim com o sumamente bom e o sumamente grande. Chegamos, pois, a uma entidade (que pode ser dita essência, substância ou natureza) maior e melhor do que tudo quanto existe: ela, e apenas ela, é summum omnium quae sunt.

\section{A terceira via tomista}

Na Suma de Teologia, depois de estabelecer a existência de um primeiro motor imóvel, causa de todo o movimento, e, seguidamente, de uma primeira causa eficiente, causa de toda a causalidade eficiente, o Doutor Angélico aplica-se em mostrar que o primeiro ser necessário por si mesmo é a causa dos demais seres. Uma vez que a causalidade respeitante à existência é a mais fundamental e necessária das formas de causa-

${ }^{4} \mathrm{Cf}$. Italo Sciuto, La ragione della fede. Il Monologion e il programma filosofico di Anselmo d'Aosta, Genova, Editrice Marietti, 1991, p. 112. 
lidade, a terceira via concretiza o sentido mais radical da causalidade eficiente. Com efeito, só é possível que algo seja causa (eficiente) do movimento de alguma coisa, ou causa eficiente de qualquer coisa se, primeiramente, existir.

As duas formulações mais apuradas da terceira via encontram-se na Suma contra os Gentios ${ }^{5}$ e na Suma de Teologia ${ }^{6}$. Ambos os textos partem da constatação de que há entes sujeitos ao movimento de geração e corrupção, que vêm à existência e que cessam de existir. Tal sujeição atesta que não são necessários, mas apenas possíveis; com efeito, a sua existência não é incompatível, em tempos diversos, com a sua inexistência.

Em uníssono no começo, as duas sumas divergem, todavia, nos passos imediatamente subsequentes. A versão da Suma contra os Gentios é habitualmente considerada mais simples e rigorosa; a da Suma de Teologia, menos linear, menos consensual. Comecemos pela primeira: nela se afirma, por constatação, que existem entes meramente possíveis. A afirmação seguinte é categórica: todo o possível tem uma causa (omne quod est possibile esse, causam habet). Explicita Tomás de Aquino que, uma vez que o ente possível está, por si mesmo, igualmente disposto à existência e à inexistência, se existe, é necessário que o seu ser seja causado por outro (cum de se aequaliter se habet ad duo, scilicet esse et non esse, oportet, si ei approprietur esse, quod hoc sit ex alia causa). Por outra parte, e de acordo com Aristóteles, é impossível regredir infinitamente na ordem das causas, pelo que há que concluir que existe um ser necessário (oportet ponere aliquid quod sit necesse esse).

Na Suma de Teologia, a argumentação prossegue noutro sentido. Há seres possíveis. Contudo, afirma Tomás, uma vez que os seres possíveis não existem desde sempre, é impossível que apenas existam seres possíveis. Por que razão não é possível que os entes desta qualidade existam desde sempre? A resposta é controversa: não é possível porque o que pode não ser, num dado momento não é (quod possibile est non esse, quandoque non est). Se todos os entes fossem meramente possíveis teria havido um momento em que nada existia (si igitur omnia sunt possibilia non esse, aliquando nihil fuit in rebus); todavia, uma vez que nada provém do nada, se tivesse havido um momento em que nada existia, ainda hoje nada existiria, pois algo só passa da inexistência à existência por intermédio de um existente em acto (non incipit esse nisi per aliquid quod est). Constatamos que existem entes possíveis, logo há que concluir que nem todos os entes são possíveis, mas que, à semelhança do que se

5 Cf. Suma contra os Gentios I 15 (in Sancti Thomae de Aquino Opera omnia iussu Leonis XIII P. M. edita, tt. 13-15, 1918-1930).

6 Cf. Suma de Teologia I q2 a3 co (in Sancti Thomae de Aquino Opera omnia iussu Leonis XIII P. M. edita, tt. 4-12, 1888-1906). 
concluíra na Suma contra os Gentios, há algum ente necessário (non omnia entia sunt possibilia, sed oportet aliquid esse necessarium in rebus).

A estrutura da segunda parte da argumentação é partilhada pelas duas sumas. A necessidade de um ente pode ser originária ou causada ${ }^{7}$ : um ente necessário é necessário ou por si mesmo ou em virtude de um outro (omnem necessarium vel habet causam suae necessitatis aliunde, vel non, sed est per se ipsum necessarium [SCG]; omne necessarium vel habet causam suae necessitatis aliunde, vel non habet [ST]). Para justificar a necessidade da existência do ser necessário por si mesmo, ambos os escritos recorrem, então, à impossibilidade de retroceder ao infinito na cadeia de seres cuja necessidade é causada; e isto analogamente ao que sucede com as causas eficientes, sublinha a Suma de Teologia, pois do mesmo modo que nada pode ser causa eficiente de si próprio, nada pode ser causa da sua própria necessidade.

A explicitação do passo seguinte surge com maior clareza na Suma de Teologia do que na Suma contra os Gentios. Neste último escrito, afirma-se que é forçoso reconhecer a existência de um primeiro ente necessário, e que seja necessário por si mesmo (oportet ponere aliquod primum necessarium, quod est per seipsum necessarium). A Suma de Teologia procura ser mais rigorosa: há que admitir a existência de um ente necessário por si mesmo, cuja causa da necessidade não esteja noutro ente, mas em si, e que seja causa da necessidade de todos os outros (necesse est ponere aliquid quod sit per se necessarium, non habens causam suam necessitate aliunde, sed quod est causa necessitatis aliis).

É certo que quando a Suma contra os Gentios estabelece a existência do primeiro ente necessário (primum necessarium) fá-lo admitindo implicitamente que ele não tem a razão da sua necessidade noutro e que é causa da necessidade dos demais - é por isso dito primeiro. Não o enuncia, no entanto, com a mesma nitidez. Poderíamos considerar tal precisão desnecessária, mas se tivermos em conta que, segundo Tomás de Aquino, Deus não é o único ser necessário, concordamos na sua conveniência. Divergentes na explicitação, as duas sumas são unânimes ao concluir: este ente absolutamente necessário deve ser identificado com aquilo a que chamamos Deus.

\footnotetext{
${ }_{7}$ Recorde-se que Tomás de Aquino entende contingência em sentido aristotélico, ou seja, como contingência física, ditada pela mutabilidade, e não como a dependência ontológica relativamente a Deus, isto é, como contingência metafísica. Entendida no primeiro sentido, a contingência é própria dos entes corruptíveis. Os entes incorruptíveis são, pois, necessários, ainda que a sua necessidade dependa da vontade divina, que assim os criou e os mantém no seu ser. Há, pois, entes necessários, mas que são metafisicamente contingentes. Para aprofundamento deste tópico, cf. Suma contra os Gentios II 30 e Jan Aertsen, Nature and Creature. Thomas Aquinas's Way of Thought, Leiden, Brill, 1988, pp. 240-246.
} 


\section{Análise comparada das terceiras vias anselmiana e tomista}

Dependendo de perspectivas filosóficas diversas, e denotando finalidades igualmente diversas, a terceira via anselmiana e a terceira via tomista partilham, porém, alguns dos passos da sua estrutura argumentativa e dos princípios metafísicos que as sustentam. Em certos momentos, a demonstração do Monologion sugere maior semelhança com a da Suma contra os Gentios; noutros, com a da Suma de Teologia. Nesta secção, damos conta da proximidade, bem como da distância, entre ambas as vias, atendendo, primeiramente, à argumentação e, em seguida, à fundamentação.

\subsection{Quanto à estrutura argumentativa}

As duas provas assumem como dado prévio a existência evidente de entes que não subsistem no seu ser. Mas embora a terceira via tomista se refira explicitamente aos entes sujeitos ao movimento de geração e de corrupção, a terceira via anselmiana não o faz. Anselmo nota que, aparentemente, tudo o que é/existe, é/existe por uma qualquer coisa (quidquid est, per unum aliquid videtur esse). Estes entes que existem por uma qualquer coisa tanto podem ser aqueles que estão sujeitos ao movimento de geração e de corrupção como quaisquer entes mutáveis, pelo que a via não é inteiramente clara: pode visar o movimento de geração e de corrupção ou toda a mutabilidade.

Por sua vez, o Aquinense, após afirmar a existência de entes que, por mostrarem igual disposição para ser e não ser, são ditos possíveis (possibilia), restringe o seu âmbito, centrando-se naqueles que são sujeitos ao movimento de geração e de corrupção (videmus in mundo quaedam quae sunt possibilia esse et non esse, scilicet generabilia et corruptibilia [SCG]; invenimus in rebus quaedam quae sunt possibilia esse et non esse: cum quaedam inveniantur generari et corrumpi et per consequens possibilia esse et non esse [ST]). Portanto, ainda que ambas as vias visem os entes possíveis no seu todo, apenas a terceira via tomista concretiza aqueles a que se refere.

Tendo observado que tudo o que é/existe parece ser/existir por uma qualquer coisa, Anselmo prossegue, fazendo apenas uso do princípio de não contradição: tudo o que é/existe, é/existe ou em virtude de alguma coisa (per aliquid), ou em virtude de nada (per nihil); nada vem ao ser, porém, a partir do nada; logo, tudo o que é/existe, é/existe por um outro. E assim conclui a primeira parte da argumentação da sua terceira via. A primeira parte da terceira via tomista recebeu, como já foi dito, duas formulações distintas, uma na Suma contra os Gentios e outra na Suma de 
Teologia. Cada uma destas versões apresenta diferentes afinidades com a terceira via do Monologion.

Em primeiro lugar, atente-se no que concerne à causalidade. Anselmo afirmara: tudo o que é/existe, é/existe em virtude de algo (per aliquid). Esta asserção remete, evidentemente, para a causalidade: tudo o que é/existe, é/existe na medida em que foi causado por um outro. Encontramos este mesmo argumento, nos mesmos termos, na Suma contra os Gentios. Após constatar a existência de entes possíveis, Tomás de Aquino conclui que o ente possível é, não por si mesmo, mas em virtude de uma causa (ex aliqua causa). O possível é, pois, para os dois autores, aquele cujo ser lhe foi dado por outro, aquele cujo ser é causado.

A etapa seguinte da Suma contra os Gentios não apresenta paralelo com a terceira via anselmiana. Com efeito, na Suma a argumentação prossegue apoiando-se na impossibilidade de retroceder ao infinito na ordem das causas e estabelece a existência de algo necessário entre as coisas. A terceira via do Monologion não toca, contudo, a questão da finitude ou infinitude da ordem das causas; antes mostra que, porque nada tem origem no nada, tudo o que é, é por um outro. Neste último ponto, a via anselmiana está mais próxima da formulação da terceira via tomista na Suma de Teologia.

O início da demonstração na Suma de Teologia não denota essa proximidade; encontramo-la somente no final da primeira parte. A constatação da existência dos entes possíveis dá lugar à afirmação de que tais entes não podem existir desde sempre, já que tudo o que pode não ser num dado momento não é. É verdade que não encontramos eco desta última justificação na terceira via do Monologion; não obstante, também não encontramos motivos suficientemente fortes para afastar a hipótese de o Doutor Magnífico concordar com ela. Seguidamente, Tomás de Aquino enuncia na sua demonstração o mesmo princípio já utilizado por Anselmo de Aosta: o nada não pode ser causa de coisa alguma. Daqui infere Anselmo que tudo vem a ser por alguma coisa; Tomás, por seu turno, que a existência dos possíveis reclama a existência de algo necessário.

Chegadas a este ponto, ambas as provas dão por finalizada a primeira parte da sua argumentação: a via anselmiana asseverando que tudo o que é existe em virtude de um outro; a via tomista (em ambas as versões), que há algo necessário entre os entes. Anselmo prossegue, então, indagando acerca do carácter uno ou múltiplo dessa causa pela qual todos os entes são/existem e mostrando que uma hipotética multiplicidade é sempre redutível a uma unidade primeira. Tomás, por seu lado, recordando que o ente dito necessário pode sê-lo por si mesmo ou em virtude de um outro e assinalando - pela primeira vez na Suma de Teologia, mas pela segunda na Suma contra os Gentios - a impossibilidade de regressão ao 
infinito na série de coisas cuja necessidade é causada, põe a claro a necessidade da existência de algo necessário por si mesmo e que seja causa da necessidade dos demais entes.

\subsection{Quanto aos princípios metafísicos}

Nesta secção, procuramos mostrar que, não obstante as diferenças observadas ao nível da formulação, as duas vias partilham os princípios metafísicos subjacentes à sua estrutura. Assinalamos, antes de mais, o princípio de identidade e não contradição, motor da sucessão das diversas alternativas expostas na terceira via anselmiana. Ainda que o reconhecimento de valor ontológico a tal princípio seja controverso, não nos furtamos a referi-lo, porque quer o Doutor Magnífico quer o Angélico lhe atribuem inequivocamente valor ontológico-metafísico, de que o valor lógico não é senão consequência.

A evocação do argumento do Proslogion bastaria para atestar que Anselmo concebe a ordem lógica como consequência da ordem ontológica; esta posição é, porém, menos nítida em Tomás. Torna-se, aliás, inevitável recordarmo-nos de imediato da sua crítica ao trânsito, quanto a ele ilegítimo, da ordem lógica para a ontológica operado no argumento úni$\mathrm{co}^{8}$, pelo que parecerá não haver razões suficientes para afirmar, neste ponto, o acordo entre ambos. E, todavia, sustentamo-lo.

Com efeito, quando Tomás de Aquino afirma que nada é cognoscível senão por semelhança com a primeira verdade ${ }^{9}$, deixa entrever que não concebe a verdade como consequência do pensamento, mas o pensamento como consequência da verdade. A primeira verdade, na sua acepção ontológica e não apenas lógica, é, pois, o fundamento de todo o pensamento e de todo o conhecimento - nisto ambos os pensadores estão de acordo. É esta concepção que permite compreender a noção tomista de uma ratio que é recta, ou seja, que atinge a sua adequatio ao apreender as coisas tal como são, na sua verdade. Por ela se entende também a importância assumida no decurso das demonstrações pelo conteúdo das definições dos pares de conceitos por si e por outro, e possivel/contingente e necessário.

Sendo o objectivo do presente estudo não o exame da validade ou invalidade das vias, mas sim a sua comparação, não nos ocupamos da valência ontológica do princípio de não contradição que, por si só, motivaria uma outra investigação, de maior fôlego; apenas apontamos a im-

${ }^{8} \mathrm{Cf}$. Suma de Teologia I q2 a1 ad2.

${ }^{9}$ De Veritate q22 a2 ad1 (in Sancti Thomae de Aquino Opera omnia iussu Leonis XIII P. M. edita, t. 22, 1972): «Nihil est cognoscibile nisi per similitudine primae veritatis». 
portância que os dois autores lhe conferem nas suas demonstrações. Pensamos que é neste princípio que se baseiam os restantes de que os santos fazem uso ${ }^{10}$ e que dele depende directamente o princípio de razão de ser, deste dependendo, por sua vez, os de causalidade e de participação, com os quais se articulam outros, oportunamente assinalados.

A dependência do princípio de razão de ser relativamente ao princípio de não contradição manifesta-se na argumentação de fundo das duas provas, as quais, partindo da contingência entendida em sentido físico, assumem essa dimensão física como sinal de contingência metafísica. $\mathrm{O}$ contingente existe, e por ser isso mesmo que é, exige uma razão de ser, sem a qual não existiria. Porém, como efectivamente existe, tem necessariamente uma razão de ser.

Dito de outro modo: quer os entes que são per aliquid quer os generabilia et corruptibilia, pelo facto de existirem em virtude de um outro e de se mostrarem incapazes de se conservarem no seu ser, denotam indubitavelmente a sua indigência ontológica. Dado poderem adquirir ou perder o ser, têm o ser, mas não são o próprio ser, pelo que a sua mera existência reclama uma razão de ser necessariamente extrínseca; e isto porque se o contingente, que não tem em si mesmo a sua razão de ser, a não tivesse num outro, seria e não seria, ao mesmo tempo. Assim, a mera existência dos contingentes coage a inteligência a reconhecer a necessidade da existência do primeiro necessário; a sua negação, ao nível da lógica, implicaria uma contradição ontológica, porque negaria o facto da existência da contingência. É por isto que, neste contexto, a afirmação do Ser Necessário é a condição transcendental da possibilidade da afirmação do ser contingente ${ }^{11}$.

Pelo que acima se disse, torna-se claro que o princípio de razão de ser compreende o de causalidade e que o contingente implica uma causa eficiente, já que não é senão em virtude de outro: non nisi per aliquid, nas palavras de Anselmo; ex aliqua causa, nas de Tomás. O ser contingente define-se por ser em virtude dessa relação, como nota Maria Leonor Xavier que, analisando a ontologia anselmiana, descortina o princípio de disposição relacional do ser por algo ${ }^{12}$ (que tomamos por derivado do princípio de razão de ser e como válido para os dois autores), cuja enun-

10 Não somos originais nesta anteposição do princípio de identidade e não contradição, seguimos Carlo Cantone (cf. Introduzione al problema di Dio. Discorso su Dio ed esperienza religiosa, Brescia, La Scuola, 1973, pp. 156-156).

11 Cf. Carlo Cantone, Introduzione al problema di Dio, p. 184.

12 Princípio valente para três modalidades da metafísica anselmiana: participação, causalidade, processão (cf. Maria Leonor Xavier, Razão e Ser. Três questões de ontologia em Santo Anselmo, Lisboa, Fundação Calouste Gulbenkian, 1999, p. 418). 
ciação causal estabelece que todo o ente é efeito de alguma causa ${ }^{13}$.

Efectivamente, quer Anselmo quer Tomás concebem a causa quanto ao ser em termos de causalidade eficiente. O primeiro adianta que esta é, a par da material e da instrumental, uma das modalidades abrangidas pela expressão esse per ${ }^{14}$; o segundo, referindo-se à sabedoria de Deus, afirma que as criaturas se comparam ao Criador como as obras de arte ao artista $^{15}$. Deste modo, as duas vias afastam a hipótese de que esse algo em virtude do qual um ente existe seja o próprio nada ${ }^{16}$. É certo que nenhum dos autores nega a criação a partir do nada e, nesse sentido, ambos têm por verdadeiro que algo possa de facto ser a partir do nada (não do nada absoluto, evidentemente, mas ex nihilo sui et subiecti); o que recusam é que o nada possa ser dito razão de ser ou causa eficiente de alguma coisa.

Excluem ainda ambos que algo possa ser causa eficiente de si próprio. Com efeito, observamos que a hipótese encerra uma contradição insolúvel, mesmo para a primeira causa, pois para que algo pudesse ser causa sui, teria que existir antes de começar a existir; uma vez existindo, porém, não haveria razão para se causar a si mesmo ${ }^{17}$. Nada pode ser causa eficiente de si mesmo porque nenhuma causa pode ser causada pelo próprio efeito ${ }^{18}$. Para Tomás, esse pensamento repugna à razão porque todo o efeito é inferior à sua causa. Afirmar que algo é causa eficiente de si mesmo seria, para Anselmo, cair no erro apontado a respeito da causalidade recíproca: trata-se de um pensamento irracional, porque nada pode ser por aquilo a que dá o ser (ut vero plura per se invicem sint, nulla patitur ratio, quoniam irrationabilis cogitatio est, ut aliqua res sit per illud, cui dat esse). Anselmo explicita-o deste modo: aquilo que existe

por outro (per aliud) é menos real do que aquilo que é por si mesmo (per

13 Cf. Maria Leonor Xavier, «O argumento anselmiano entre continuadores e críticos», p. 271.

14 Cf. Monologion 6: «Quod enim dicitur esse per aliquid, videtur esse aut per efficiens aut per materiam aut per aliquod aliud adiumentum, velut per instrumentum».

15 Suma contra os Gentios II 24: «Comparantur igitur omnes res creatae ad Deum sicut artificiata ad artificem».

16 Para uma melhor compreensão das diversas acepções em que a disjunção per aliquid - per nihil, apresentada por Anselmo, pode ser tomada, bem como a sua dupla significação quer exclusiva quer inclusiva, cf. Monologion 6 ss. e Maria Leonor Xavier, Razão e Ser, pp. 413-425.

17 Cf. Suma de Teologia I q2 a3 co; Mark Nowacki, «Whatever comes to be has a cause of its coming to be. A thomist defence of the principle of sufficient reason», in The Thomist 62 (1998), 291-302, nota 25.

18 A designação assinalada é a utilizada por Maria Leonor Xavier para explicitar a forma causal do princípio da assimetria da relação por algo (cf. Razão e Ser, pp. 450-463; «O argumento anselmiano entre continuadores e críticos», p. 271). 
se); pelo que se consideramos a causa primeira, há, sem dúvida, que concluir que ela é maior do que qualquer dos seus efeitos (at quidquid est per aliud, minus est quam illud per quod cuncta sunt alia, et quod solum est per se).

Os dois autores postulam igualmente a necessidade da redução da multiplicidade à unidade. Anselmo, a respeito das três hipóteses que avança para uma possível multiplicidade da causa primeira, afasta a última (a causalidade recíproca) por ser irracional e também as duas primeiras, mostrando que, na verdade, outra coisa não fazem senão remeter a multiplicidade para uma qualquer força ou natureza em virtude da qual tudo é. Não deixa de ser curioso que Tomás de Aquino, não na terceira via, mas no segundo livro da Suma contra os Gentios, proceda de modo semelhante para eliminar a hipótese de uma causa múltipla da existência. Depois de assinalar que o incausado é, relativamente ao causado, primeiro e imediato, existindo em virtude de si mesmo, observa que é impossível que algo se diga de duas coisas segundo o seu próprio ser, sendo necessário ou que uma seja a causa da outra ou que ambas sejam efeitos de uma terceira. A causalidade recíproca é impossível porque, justifica, não podendo nenhum dos dois (que neste caso seriam, simultaneamente, causas e causados) exceder o outro, nenhum será em razão do seu próprio ser. Acrescenta que, no que concerne ao ser, dado que respeita a tudo quanto é, é necessário que tudo o que é proceda daquele que não tem causa de ser (oportet igitur quod ab illo cui nihil est causa essendi, sit omne illud quod quocumque modo est); do mesmo modo que o fogo é causa da chama de duas velas, a causa do acto de ser de dois entes terá que ser o próprio acto de $\operatorname{ser}^{19}$.

Atentemos agora no modo como as duas vias se situam quanto ao princípio da finitude da ordem das causas. A posição de ambas é mais linear a respeito da necessidade da redução do múltiplo ao uno do que quanto a este princípio. Tenha-se presente o silêncio já assinalado da via anselmiana: ela não contesta nem assume abertamente a possibilidade de uma série temporal infinita. Contudo, não podemos deixar de assinalar que uma vez que a quarta via, exposta no capítulo imediatemente seguinte, e intitulado «De eadem re», se estrutura com base no princípio da finitude da ordem qualitativa das naturezas, há fortes razões para supor que a finitude da ordem das causas se encontre latente na terceira ${ }^{20}$.

Tomás, como é sabido, não encontra para lá do domínio da fé razões suficientemente sólidas para refutar a possibilidade, puramente teórica, da eternidade do mundo. É certo que, considerando quer os possíveis quer as

19 Cf. Suma contra os Gentios II 15.

20 Cf. Maria Leonor Xavier, «O argumento anselmiano entre continuadores e críticos», p. 273 
séries desses mesmos entes possíveis, tal hipótese seria, à luz dos princípios metafísicos enunciados, falha de sentido. Com efeito, segundo a definição de contingente (individual), este corrompe-se e, por isso mesmo, num dado momento não é (quandoque non est [ST]) - por outras palavras, o que é contingente tem necessariamente um começo e um fim. E tal é exigido pelo princípio de não contradição, pois se o corruptível não se corrompesse seria, de facto, incorruptível ${ }^{21}$; quer o contingente quer as hipotéticas séries infinitas de contingentes seriam, não contingentes, mas necessários. E porque o contingente é, por definição, causado, afirmar uma série contingente infinita seria afirmar que ela não tem uma causa ou um fundamento; consequentemente, entrar-se-ia em contradição - para a evitar, há que sair dessa série contingente e reconhecer que ela tem uma causa, que lhe é transcendente ${ }^{22}$.

Mas o que dizer a respeito da hipotética eternidade dos entes necessários? Sabemos que Tomás de Aquino entende não haver contradição racional entre a acção criadora de uma causa primeira e a eternidade dos seus efeitos, chegando a afirmar a existência de criaturas efectivamente necessárias, porque incorruptíveis. Sabemos também que concorda com Anselmo na necessidade de redução da multiplicidade à unidade. Neste sentido, reconhece que, assim como nas ciências demonstrativas os princípios necessários são causa de conclusões necessárias, sem os quais estas não existiriam, mesmo os entes necessários têm forçosamente uma causa pela qual são necessários ${ }^{23}$. Para Tomás, portanto, e em virtude da necessária redução da multiplicidade à unidade, os efeitos, mesmo os necessários, não existiriam sem uma causa eficiente, pelo que mesmo que não possamos afirmar, à luz da razão no seu funcionamento autónomo, um começo físico (no tempo) não podemos não afirmar o começo metafísico de todo aquele que não é a primeira causa, pelo que mesmo os entes fisicamente necessários são metafisicamente contingentes. Assim, quando Tomás alude à finitude da série de seres necessários cuja necessidade é causada, transporta-nos, de um só golpe, da física para a metafísica, pois não é, efectivamente, de um começo temporal aquele de que se trata.

Embora nem Anselmo nem Tomás o enunciem e possa passar despercebido a uma primeira leitura, há a assinalar, em estreita conexão com o princípio de causalidade, a presença do princípio de participação. A causalidade implica, por si só, a participação, já que não pode não haver

21 Cf. De coelo et mundo I Lect. $29 \mathrm{n} 8$ (in Sancti Thomae de Aquino Opera omnia iussu Leonis XIII P. M. edita, t. 3, 1886): «Impossibile est id quod est corruptibile quandoque non corrumpi, quia si quandoque non corrumpitur, potest non corrumpi et ita erit incorruptibile».

22 Cf. Carlo Cantone, Introduzione al problema di Dio, p. 185.

23 Cf. Suma de Teologia I q44 a1 ad2. 
uma semelhança, mesmo que ínfima, entre a causa e o causado. Deste modo, ainda que a participação não implique a causalidade, a causalidade implica a participação; por este motivo pode afirmar-se, mesmo que apenas no sentido acima referido, que a causalidade é, por si mesma, uma forma de participação ${ }^{24}$.

A maior evidência desta relação é assinalada por Tomás de Aquino no caso específico da causalidade eficiente, a qual, afirma, implica a participação, na medida em que todo o agente produz sempre algo semelhante a si mesmo, sendo a maior ou menor semelhança entre a causa e o causado resultante da maior ou menor proximidade entre a forma de ambos ${ }^{25}$. Todas as perfeições do efeito devem, por conseguinte, encontrar-se na sua causa eficiente, na qual preexistem virtualmente ${ }^{26}$.

Ambos os autores assumem que possuir uma perfeição incompletamente é o mesmo que tê-la a partir de uma causa ${ }^{27}$; é participar dessa causa, da qual dependemos essencialmente, mas que nos excede absolutamente $^{28}$. Sendo o efeito o próprio ser, a causa eficiente deve ser o ser em grau sumo. Concluiu-se anteriormente que os entes possíveis (e até mesmo os necessários) de que partem as duas provas possuem imperfeitamente o ser (esse): têm-no, mas não o são, são per aliud. Concluir-se-á agora, portanto, que são necessariamente participantes do primum esse per se necessarium.

24 Para compreender a tripla acepção - platónica, aristotélica, aviceniana - em que o princípio de participação pode ser tomado no pensamento tomista e sua articulação com o princípio de causalidade, cf. De Potentia q3 a5 co (in Quaestiones disputatae, t.2, Editrice Marietti, 1953) e, para a sua análise, Cornelio Fabro, La Nozione Metafisica di Partecipazione, in Opere Complete, Roma, EDIVI, 2005, pp. 119-120. É de frisar que Tomás de Aquino concebe estes três sentidos como complementares.

25 Explica São Tomás (Suma de Teologia I q4 a3 co) que, quando o agente e o efeito são da mesma espécie, há coincidência na razão específica. Há, porém, casos em que o agente não é da mesma espécie do efeito, como o que é gerado pelo calor do Sol não é da mesma espécie do Sol; neste caso, a sua forma é semelhante não quanto à espécie, mas quanto ao género. Mas quando se trata de uma causa agente que não tem nem a espécie nem o género em comum com o efeito por ela causado, a semelhança entre ambos será ainda mais distante, apenas segundo uma qualquer analogia (secundum aliqualem analogiam), assim como o ser é comum a tudo - e é por isso que os entes se assemelham a Deus, como primeiro e universal princípio de todo o ser (sicut ipsum esse est commune omnibus. Et hoc modo illa quae sunt a Deo, assimilantur ei inquantum sunt entia, ut primo et universali principio totius esse).

26 Cf. Suma de Teologia I q4 a2 co.

27 Cf. E. Gilson, Le Thomisme, p. 86. Gilson refere-se especificamente à quarta via e a São Tomás, mas consideramos que a observação vale também para Anselmo.

28 Cf. Cornelio Fabro, La Nozione Metafisica di Partecipazione, p. 344. 


\section{Apreciação final}

A análise comparada da terceira via anselmiana e da terceira via tomista permite-nos observar que as semelhanças se apresentam em maior número e com maior peso do que as diferenças. Observe-se, primeiramente, que ambas concretizam a atitude, herdada de Agostinho, posteriormente legada à Escolástica por Anselmo, da fé que procura a sua inteligibilidade; observe-se, da mesma maneira, que, não obstante a sua dependência da fé, se procuram fundamentar exclusivamente na luz natural da razão ${ }^{29}$.

$\mathrm{O}$ itinerário percorrido em cada uma é formalmente idêntico. A via anselmiana procede dos múltiplos para o uno - por outras palavras, parte dos múltiplos entes ou existentes para chegar a concluir que, na sua raiz, está forçosamente um primeiro Ente ou Existente que não pode ser senão um. A via tomista caminha dos entes para o Ente, dos existentes para o Existente - deixando perceber que esse primeiro Ente ou Existente não pode ser senão necessário.

Uma leitura atenta permite constatar a unanimidade das duas conclusões. Na verdade, o um concluído na via anselmiana é o existente necessário; e $o$ existente necessário concluído na via tomista não pode ser senão um. É certo que Anselmo enfatiza a unidade da primeira causa e Tomás a sua necessidade, mas o uno é indubitavelmente necessário, e o necessário é forçosamente um. Aliás, o Doutor Angélico fez questão de o afirmar na

29 Note-se, contudo, que esta tentativa de recorrer apenas à razão não deve ser interpretada como defesa da autonomia desta faculdade em sentido absoluto. Isto vale quer para o pensamento anselmiano quer para o tomista. É inegável que o Doutor Magnífico construíu uma teologia natural, porque teológica, quanto ao objecto, e filosófica quanto ao método (argumentativo), exclusivamente fundado em princípios racionais (a necessidade da razão e a clareza da verdade), como desde logo havia anunciado no Prólogo do Monologion (cf. Maria Leonor Xavier, «A dizibilidade de Deus segundo o Monologion de Santo Anselmo», in Joaquim Cerqueira Gonçalves (coord.), Pensar a Cultura Portuguesa. Homenagem ao Prof. Doutor Francisco José da Gama Caeiro, Lisboa, Colibri - Dep. de Filosofia da F. L. U. L., 1993, p. 316; «O argumento anselmiano entre continuadores e críticos», p. 269). No entanto, é também verdade que Anselmo adverte o leitor, neste mesmo Prólogo, de que o conteúdo do seu opúsculo não deve ser considerado correcto senão na medida em que não se afaste dos ensinamentos dos Padres da Igreja (em particular dos de Santo Agostinho, no De Trinitate) e, mais adiante, no primeiro capítulo, de que a necessidade dos seus argumentos não deve ser considerada absoluta, mas sim relativa à autoridade. Encontramos igualmente esta mesma posição no Doutor Angélico apesar de, pela autonomia que concede à razão, ser frequentemente apontado como um dos precursores da laicização da razão. É certo que Tomás afirma que a verdade racional não contraria a fé cristã e que o que é ínsito à razão se mostra de tal modo verdadeiro que não permite sequer supor a sua falsidade (cf. Suma contra os Gentios I 7); acrescenta, porém, que é ainda menos legítimo ter por falso o que recebemos pela fé, já que foi confirmado por Deus, deixando entender que, em caso de conflito entre a fé e a razão, se deve salvaguardar a fé, devido à falibilidade da razão (cf. Suma de Teologia I q1 a5). 
segunda parte da Suma contra os Gentios. Se o final da exposição da terceira via nesta obra e na Suma de Teologia permite compreender que esse primeiro necessário é um, no capítulo quinze da segunda parte da Suma contra os Gentios, após um breve resumo da terceira via, lê-se explicitamente que este ser necessário por si mesmo, fundamento de todos os possíveis e de todos os necessários, não pode ser senão um (nisi unum) ${ }^{30}$.

Vendo a unidade como razão lógico-ontológica da multiplicidade, ambos os autores fazem sua a trave-mestra da ontologia parmenideana e platónica ${ }^{31}$. Estamos cientes de que esta afirmação é menos consensual a respeito da ontologia de Tomás de Aquino do que da ontologia de Anselmo de Aosta; não obstante, encontramos na obra do Angélico razões suficientes para a sustentar. O santo não se esforça por escamotear a influência de Platão no seu pensamento; quando trata de afirmar que a unidade precede toda a multiplicidade, recorre à autoridade do ateniense ${ }^{32}$. Platónica é também a valorização ontológica da matemática, de que se serve para justificar a unidade da causa primeira: tomando como exemplo o número seis, esclarece que a natureza e a razão de ser deste não resulta da adição ou multiplicação dos números dois e três - já que assim teríamos múltiplas substâncias - mas da própria unidade ${ }^{33}$, que a tudo preside.

É a insuficiência ontológica dos múltiplos contingentes que leva Anselmo e Tomás a afirmarem a existência do primeiro necessário, pelo que estamos perante demonstrações efectivamente existenciais. Em terminologia tomista, podemos dizer que na terceira via anselmiana o ente é, de facto, concebido como um ser finito, realmente composto de essência e

30 Suma contra os Gentios II 15: «Tudo o que pode ser e não ser tem alguma causa, porque, considerado em si mesmo, é indiferente a uma e a outra possibilidade; e assim é necessário que haja alguma causa que o determine a uma delas. Donde, não sendo possível a regressão ao infinito, é forçoso que exista algo necessário que seja causa de todos os que podem ser e não ser. Mas uma coisa é necessária quando tem causa da sua necessidade, no que tampouco se pode regredir ao infinito; sendo, portanto, preciso chegar a algo que seja, por si, necessário. Este não pode ser senão um [...]» (Omne quod est possibile esse et non esse, habet causam aliquam: quia in se consideratum ad utrumlibet se habet; et sic oportet esse aliquod aliud quod ipsum ad unum determinet. Unde, cum in infinitum procedi non possit, oportet quod sit aliquid necessarium quod sit causa omnium possibilium esse et non esse. Necessarium autem quoddam est habens causam suae necessitatis: in quo etiam in infinitum procedi non potest; et sic est devenire ad aliquid quod est per se necesse esse. Hoc autem non potest esse nisi unum [...]).

31 Tomamos a expressão de Cornelio Fabro. Embora, no seu contexto, se refira especificamente ao pensamento tomista, aplicamo-la também ao pensamento anselmiano (cf. La Nozione Metafisica di Partecipazione, p. 72).

32 Suma de Teologia I q44 a1 co: «Unde et Plato dixit quod necesse est ante omnem multitudinem ponere unitatem [...]».

33 Cf. De substantiis separatis 10 (in Sancti Thomae de Aquino Opera omnia iussu Leonis XIII P. M. edita, t. 40, 1968). 
de existência, cujo actus essendi não pode ser por si radicalmente originado ou mantido. A ontologia e a metafísica de Anselmo estarão assim, segundo parece, para lá da alternativa essencialismo vs. Existencialismo. Sendo o bem permutável com o ser, a tentativa de atribuir prioridade a um ou a outro seria certamente vista pelo Doutor Magnífico como sinal de incompreensão, não apenas do terceiro argumento, mas do sentido dos quatro apresentados no Monologion ${ }^{34}$.

E não o seria também para Tomás? Na verdade, as terceiras vias de Anselmo de Aosta e de Tomás de Aquino, vias da existência, possibilitam a demonstração que respeita aos graus de perfeição das naturezas - ou, dito de outra maneira, aos graus de perfeição dos existentes. A terceira via anselmiana é precedida pela via da bondade e pela via da grandeza, que têm por base a teoria platónica da participação; a terceira via tomista, pela via do movimento e pela via da causa eficiente, ambas fundamentadas na causalidade eficiente. Anselmo e Tomás chegam, pois, por percursos diversos, à via da existência. Mas dela fazem o fundamento da quarta, que, mostrando a suma perfeição desse primeiro existente necessário encontrado na terceira, é como o seu coroamento.

\section{RESUMO}

O estudo que apresentamos consiste numa análise das terceiras vias anselmiana e tomista, duas vias existenciais, já que nelas a existência é o ponto de partida e o de chegada. O percurso de ambas é essencialmente idêntico, conduzindo a existência do ente possível à conclusão da existência do primeiro ente necessário. A sua leitura comparada revela um maior número de convergências do que de divergências quer quanto à estrutura argumentativa quer quanto à fundamentação metafísica. Com efeito, os princípios metafísicos que as sustentam - identidade e não contradição, razão de ser, causalidade, participação - são os mesmos, ainda que formulados de modo diverso.

\section{RÉSUMÉ}

Notre étude consiste dans une analyse des troisièmes voies anselmienne et thomiste, deux voies existentielles, puisqu'en elles l'existence est le point de départ et le point d'arrivée. Sa route est essentiellement identique: dans les deux l'être possible conduit à conclure l'existence de l'être nécessaire. Sa lecture comparée laisse comprendre l'existence d'un plus grand nombre de convergences que de divergences en ce qui concerne à la structure argumentative et aux fondements métaphysiques. En effet, les principes métaphysiques que soutiennent les deux voies - identité, raison d'être, causalité, participation - sont identiques, bien que formulés diversement.

34 Cf. Italo Sciuto, La ragione della fede, pp. 118-119. 